MATEC Web of Conferences 47, 03006 (2016)

DOI: $10.1051 /$ matecconf/20164703006

(C) Owned by the authors, published by EDP Sciences. 2016

\title{
Pedestrian Footpath Level of Service (FOOT-LOS) Model for Johor Bahru
}

\author{
Basil David Daniel ${ }^{1, a}$, Siti Naquiyah Mohamad Nor ${ }^{1}$, Munzilah Md Rohani ${ }^{1}$, Joewono Prasetijo ${ }^{1}$, \\ Mohamad Yusri Aman ${ }^{1}$ and Kamarudin Ambak $^{2}$ \\ ${ }^{1}$ Faculty of Civil and Environmental Engineering, Universiti Tun Hussein Onn Malaysia, 86400 Parit Raja, Johor, \\ Malaysia. \\ ${ }^{2}$ Smart Driving Research Centre, Universiti Tun Hussein Onn Malaysia, 86400 Parit Raja, Johor, Malaysia
}

\begin{abstract}
Pedestrian level of service (LOS) is an overall measure of walking conditions on a route, path, or facility. This is linked directly to factors that affect mobility, comfort and safety, reflecting pedestrian's perceptions of the degree to which the facility is pedestrian-friendly. A unique model called FOOT-LOS (short for pedestrian footpath level of service) was developed to facilitate the LOS measurement. The factors considered fall into three categories; physical, location and user attributes. Pedestrian conditions can be described through a grading system, i.e. from LOS A (ideal pedestrian condition) to LOS F (unsuitable pedestrian condition), based on an assessment of the factors affecting LOS. The assessment includes desktop and on-site assessment of LOS factors. The development of the model involved an iterative process that included testing and refinement. The research undertaken and the LOS model developed provide a sound basis for the measurement of LOS for pedestrian footpaths. The model not only provides a methodology for determining LOS, but also determines which factors predominantly contribute to the LOS of pedestrian footpaths.
\end{abstract}

\section{Introduction}

Walking is a means of active transportation that is healthy and sustainable. Residents in pedestrianoriented cities were found to be healthier than private automobile-oriented cities [1], and areas with improved walkability rates resulted in better air quality [2]. Local authorities strive to create walkable cities by providing pedestrian facilities such as pedestrian footpaths, footbridges and crossings.

The level of service (LOS) for pedestrians can be defined as a measurement of the condition of walkway in a road and around public areas. This relates directly to factors that can affect the movement of pedestrians, and their perceptions on comfort and safety while walking. The purpose of this study was to identify the factors that can influence the perception of pedestrians in terms of safety and comfort, and to come up with a model that can be utilised in determining the LOS of a footpath.

To achieve the aforementioned objectives, 25 streets in Johor Bahru that have pedestrian footpaths were selected. These locations represent the diversity of characteristics of footpaths in Johor Bahru, which were rated from poor to excellent in terms of levels of comfort and safety by pedestrians in a survey that was conducted at the study sites.

\footnotetext{
${ }^{a}$ Corresponding author : basil@uthm.edu.my
} 


\section{Research Motivation}

Pedestrianisation is a technique that aims to encourage walking among city folk by segregating pedestrians from vehicle traffic and providing idyllic walking environments. In Malaysia, pedestrianisation is not given enough attention since much of the city infrastructure is dedicated to road networks that predominantly cater to private automobiles. Local authorities are often in a bind when dealing with meeting demands for both vehicle traffic and pedestrians. Unsurprisingly, it is the infrastructure for vehicles that normally receives precedence over pedestrian needs [3].

Johor Bahru is a bustling city situated in the south of Peninsular Malaysia, boasting a population of nearly half a million people. While travelling by private automobiles is the foremost choice of transportation among city commuters, walking is also a mode of travel for those who cannot afford cars and those who opt to travel by foot to avoid traffic jams and crowded buses, for environmental reasons, and for travel over short distances. Most downtown streets in Johor Bahru have pedestrian footpaths, but not all are as idyllic as one would hope for (see Figure1). There is a need to regularly monitor the performance of pedestrian footpaths in order to ensure that pedestrians feel safe and comfortable when using these facilities. This in return would encourage more city folk to walk and reduce dependence on motorised travel. Hence, this study was conducted with the goal of producing a pedestrian level of service model, i.e. FOOT-LOS, for the evaluation of pedestrian LOS along footpaths.
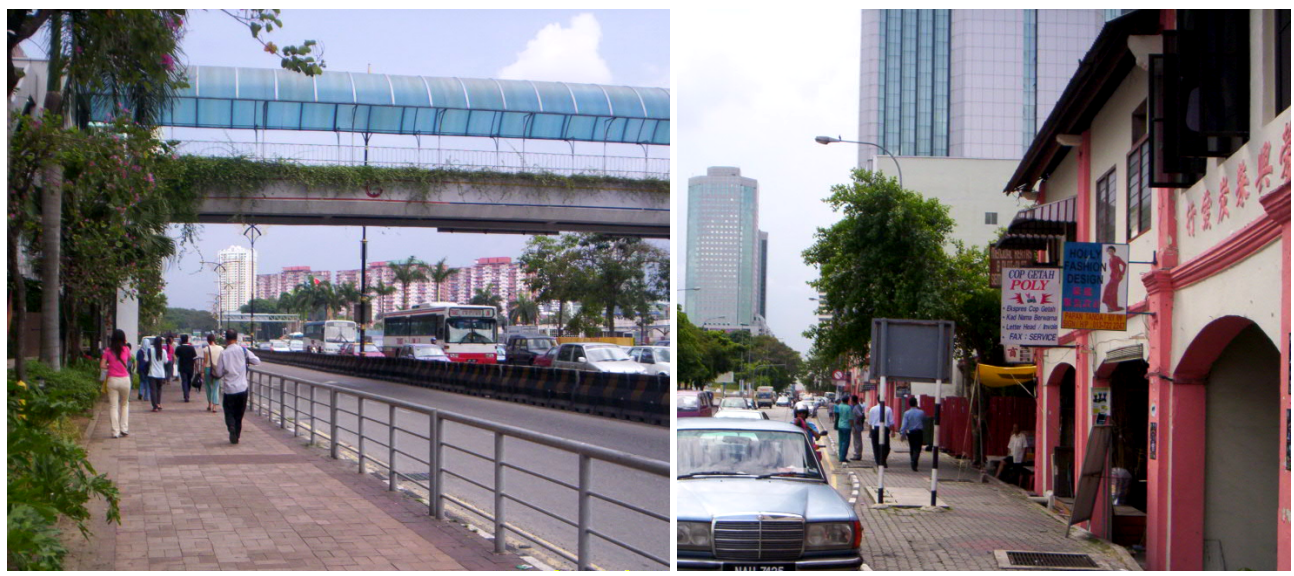

Figure 1. Contrasting conditions of footpaths in Johor Bahru.

\section{Factor Affecting Pedestrian Comfort and Safety}

A study by Florida Department of Transportation managed to identify a number of factors that can affect pedestrian safety and comfort in a roadway. The factors included lateral clearance between pedestrians and traffic, traffic volume, vehicle speed and type of vehicle [4]. Vehicle-pedestrian interaction is an important factor to consider, given that motorist behaviour influences the risk of conflicts between vehicles and pedestrians [5]. Similarly for other pedestrian facilities such as crossings, it was found that pedestrian flow, surface condition and walkway width exerted some influence on pedestrian perception of comfort and safety [6].

In Malaysia, guidance for pedestrian facilities is provided by Jabatan Kerja Raya (JKR). Ideally, width of footpaths shall be 2.4 meters or greater, while the allowable minimum width is 0.9 meters. Footpaths shall have a height clearance of 2.0 meters or more, and lateral clearance of at least 1.0 meters from the traffic lane edge. The elimination of physical obstructions, minimising of changes in level, and surface skid resistance are also considered when providing pedestrian footpaths [7]. Good walkways usually have comfortable surfaces without cracks, depressions and bumps. As a result, pedestrians will have ease of travel when using walkways that have good surface quality [8]. 


\section{Methods and Findings}

\subsection{Data collection}

On-site measurements were conducted at 25 roads in the city of Johor Bahru, to obtain footpath and road widths. Manual counts were carried out to determine the volume of both pedestrians and vehicles, while a speed meter was used to measure vehicular speed. Pedestrian flows were determined from video recordings, while obstructions and surface condition of the footpaths were quantified by visual walkthrough surveys.

391 pedestrians between the ages of 18 and 50 years were randomly interviewed at the study locations and asked to rate the footpaths in terms of comfort and safety from the scale of 1 (poor) to 5 (excellent). This sample size was well sufficient as it exceeded the 370 sample size proposed by Krejcie \& Morgan. 54\% of the respondents used the footpaths regularly to get to work and college, while the remainder used the footpaths occasionally for shopping and recreational activities.

\subsection{Model development}

Initially, the FOOT-LOS model included seven contributory factors, i.e. pedestrian flow, traffic volume, footpath width, road width, vehicle speed, percentage of surface damage and number of obstructions. Multiple linear regression analysis was applied to relate pedestrian rating with these factors.

For this purpose five assumptions were made, i.e. the relationship between the independent and dependent variables were assumed to be linear, the variables were assumed to be normal, there was little or no multicollinearity in the data, there was little or no autocorrelation in the data and the error terms along the regression line were equal or homoscedastic. After numerous runs, it was found that by excluding vehicle speed (S) and pairing some of the factors, a significant model could be produced. Hence, the FOOT-LOS model took the form of:

$$
F O O T-L O S=0.7078(F W+R W)-0.2138(S D+O B S)-0.1909\left(\frac{P+V}{1000}\right)^{2}
$$

where: FOOT-LOS = pedestrian footpath level of service rating, $\mathrm{FW}=$ footpath width (meter), $\mathrm{RW}=$ road width (meter), $\mathrm{SD}=$ surface damage $(\%$ of area), $\mathrm{OBS}=$ number of obstructions (number per 100 meter), $\mathrm{P}=$ pedestrian flow (pedestrians/minute/meter), and $\mathrm{V}=$ traffic volume (vehicles/hour).

The FOOT-LOS model yielded a coefficient of determination $\left(\mathrm{R}^{2}\right)$ value of 0.97 , which indicates that $97 \%$ of the variance in footpath level of service is predictable from the contributory factors. The F-test for significance of the regression parameters produced a Sig.F value of 0.000 , showing that the FOOT-LOS model has statistically significant predictive capability. The parameter coefficients were tested for significance using t-tests and were found to be statistically significant, with the P-values below the significance level of 0.05 (see Table 1). This implies that the parameters are good predictors of the FOOT-LOS rating.

Table 1. Results of t-test for significance of FOOT-LOS model parameter coefficients.

\begin{tabular}{cccc}
\hline Parameter & Coefficient & t-Statistic & P-value \\
\hline FW, LW & 0.7078 & 12.721 & 0.000 \\
SD, OBS & -0.2138 & -2.249 & 0.035 \\
P, V & -0.1909 & -2.096 & 0.005 \\
\hline
\end{tabular}

The FOOT-LOS model can ultimately be used to determine the numeric rating of the level of service. Alternatively, the scores can be translated to letter grades ranging from A (excellent) to $\mathrm{F}$ (poor), as shown in Table 2. 
Table 2. FOOT-LOS rating scale.

\begin{tabular}{cc}
\hline Level of Service & FOOT-LOS Score \\
\hline A & $\mathrm{x}>8.5$ \\
B & $7.0<\mathrm{x} \leq 8.5$ \\
C & $6.0<\mathrm{x} \leq 7.0$ \\
D & $5.0<\mathrm{x} \leq 6.0$ \\
E & $4.0<\mathrm{x} \leq 5.0$ \\
F & $\mathrm{x} \leq 4.0$ \\
\hline
\end{tabular}

\subsection{Model validation}

While the aforementioned statistical tests give credence to the predictive capability of the FOOT-LOS model, further validation is necessary. Footpaths on eight additional streets were randomly selected to test the accuracy between observed FOOT-LOS scores and predicted FOOT-LOS scores, which employed the model that was developed from this study (Equation (1)). As shown in Table 3, the predicted values were not far off the observed values, resulting in residuals that were relatively small.

Table 3. Observed and predicted FOOT-LOS score for model validation.

\begin{tabular}{cccc}
\hline \multirow{2}{*}{ Road Name } & \multicolumn{2}{c}{ FOOT-LOS Score } & \multirow{2}{*}{ Residual } \\
\cline { 2 - 3 } & Observed & Predicted & \\
\hline Jalan Ibrahim Sultan & 6.1 & 6.6 & -0.5 \\
Jalan Stulang Darat & 7.8 & 7.8 & 0.0 \\
Jalan Sawmill & 6.4 & 6.9 & -0.5 \\
Jalan Tampoi & 6.9 & 6.6 & 0.3 \\
Jalan Datin Halimah & 7.6 & 7.7 & -0.1 \\
Jalan Pasar & 5.3 & 5.6 & -0.3 \\
Jalan Abdullah Ibrahim & 7.5 & 7.5 & 0.0 \\
Jalan Tan Hiok Nee & 6.8 & 6.9 & -0.1 \\
\hline
\end{tabular}

\section{Conclusion}

The findings of this study show that pedestrian's perception of comfort and safety is significantly influenced not only by the walking environment and conditions, but also the adjacent road and traffic characteristics. Also, the FOOT-LOS model developed in this study was proven to be a reliable tool for quantifying the level of service of pedestrian footpaths and thus, the model can be used for performance analysis of such facilities.

Based on the FOOT-LOS model, a high level of service may be achieved if the width of pedestrian footpath is increased meet ideal specifications so that pedestrian flow is smoother and conflicts between pedestrians are minimised, the footpath is regularly maintained to provide a surface of acceptable walking quality, fixed elements that obstuct pedestrians removed from the footpath, and lateral separation between pedestrians and traffic is provided to reduce qualms regarding pedestrian safety.

\section{References}

[1] R. Ewing, T. Schmid, K. Killingsworth, A. Zlot and S. Raudenbush, Relationship between urban sprawl and physical activity, obesity and morbidity, American J. of Health Promotion, 18(1), 4757, (2003). 
[2] L. Frank, S. Kavage and T. Litman, Promoting public health through smart growth: Building healthier communities through transportation and land use policies, Smart Growth British Columbia, (2006).

[3] K. Singaravelloo, Local Government and Intergovernmental Relations, in N.A. Siddiquee (Ed.), Public Management and Governance in Malaysia: Trends and Transformations, Routledge, (2012).

[4] B.W. Landis, V.R. Vattikuti, R.M. Ottenberg, D.S. McLeod and M. Guttenplan, Modeling the Roadside Walking Environment: A Pedestrian Level of Service, Transportation Research Record No. 1773, Part 2: Bicycle and Pedestrian Research, Transportation Research Board, Washington, (2001).

[5] I. Wahab, Teknik Sistem Lalu Lintas and Pengangkutan, Dewan Bahasa dan Pustaka, Kuala Lumpur, (1997).

[6] B.D. Daniel, S.L. Choong, K. Ambak and M.E. Abdullah, Pedestrian level of service for crosswalks at signalized intersections, Proceedings of the National Seminar on Civil Engineering Research, Universiti Teknologi Malaysia, Skudai, (2007).

[7] Jabatan Kerja Raya, A Guide on Geometric Design of Roads, Arahan Teknik (Jalan) 8/86, Kuala Lumpur, (1986).

[8] C.A. O'Flaherty, Transport Planning and Traffic Engineering, Butterworth Heinemann, (1997). 